\title{
ATIVISMO JUDICIAL: POSTURA DISCRETA DO PODER JUDICIÁRIO
}

\author{
Ana Luiza Brito Viana \\ Luanna Victória Silva Dourado \\ José Carlos Melo Miranda
}

\begin{abstract}
ABBOUD, Georges; MENDES, Gilmar Ferreira. Ativismo Judicial: Notas Introdutórias a Uma Polêmica Contemporânea. Revistas dos Tribunais Online, vol. 108, n. 1008, p. 01-09, 2019.
\end{abstract}

STRECK, Lenio Luiz.; BARRETO, Vicente de Paula.; OLIVEIRA Rafael Tomaz de. Ulisses e o canto das sereias: sobre ativismos judiciais e os perigos da instauração de um terceiro turno da constituinte. Revista de Estudos Constitucionais, Hermenêuticos e Teoria do Direito, vol. 1, n. 2, p. 01-09, Jul-Dez.2009. Disponível em: https://doi.org/10.4013/47. Acesso em: 10 jan. 2020.

Os artigos “Ativismo Judicial: Notas Introdutórias a Uma Polêmica Contemporânea”, escrito por Georges Abboud (Doutor e Mestre em Direito) e Gilmar Ferreira Mendes (Ministro do Supremo Tribunal Federal e Professor de Direito Constitucional); e "Ulisses e o canto das sereias: sobre ativismos judiciais e os perigos da instauração de um terceiro turno da constituinte", escrito por Lênio Luiz Streck (jurista e advogado), Vicente de Paulo Barreto (Professor de Direito) e Rafael Tomaz de Oliveira (Professor de Direto), abordam questões do ativismo judicial no Brasil com ênfase nos riscos que a prática desse fenômeno pode acarretar para o Estado Democrático de Direito.

No primeiro texto, Abboud e Mendes (2019) trazem a explicação do que seria o ativismo judicial, bem como a diferença de como o termo é tratado no Brasil e nos Estados Unidos da América (EUA). No que tange ao significado do termo, os autores têm o objetivo de deixar claro o conceito de ativismo judicial e quais os perigos que a sua prática traz, para, desse modo, evitar que possam ser tomadas decisões que não estejam de acordo com a Constituição Federal de 1988, isto é, evitar decisões discricionárias advindas dos julgadores.

$\mathrm{O}$ ativismo judicial é tratado de maneira diferente no Brasil e nos Estados Unidos, mas não se pode negar, afirmam os autores, que toda a temática dessa matéria se estrutura no embate entre o judicial review e o judicial self restraint. Em outras palavras, pode-se dizer que há um choque existente entre a possibilidade de leis serem anuladas por não serem constitucionais versus a separação de poderes que precisa necessariamente ser respeitada.

Entretanto, os autores esclarecem que exercer ou não o controle de constitucionalidade não pode ser caracterizado por si só como ativismo judicial, uma vez que a nossa Constituição, diferente da Constituição dos Estados Unidos, traz expressamente previsto o controle de constitucionalidade. Nesse contexto, é mais fácil distinguir o que seria ativismo judicial de posturas judiciais que são legítimas, fundamentadas na Constituição Federal de 1988 e, portanto, representam respeito à ordem democrática. 
Dessa forma, é possível - e fácil - perceber que no Brasil, o ativismo judicial representa uma conduta diversa do que, de fato, deveria ser. Essa expressão retrata uma substituição do direito imposto na Constituição e nas leis, tão somente pela subjetividade de quem está julgando, baseado em preceitos morais, ideológicos e políticos. Nesse sentido, Tassinari (2012), afirma que o ativismo judicial representa no Brasil o que Lênio Streck entende pela expressão, quer dizer, o ativismo judicial é uma deturpação do poder judiciário que passa a atuar extrapolando os limites que são estabelecidos nas suas funções.

Outro ponto importante tratado ainda no primeiro artigo diz respeito ao que os autores chamam de “bom ou mau ativismo". Para eles, por se tratar de uma atividade perniciosa ao Estado Democrático de Direito, não há que se falar em ativismo bom ou ativismo ruim, sendo qualquer prática ativista danosa à democracia e vazia de ideologia, devendo sempre, em qualquer hipótese, ser evitada. Vale ressaltar que pouco importa se o julgador tende a ser progressista ou conservador, se ele decidir com base em suas convicções pessoais, por razões morais, ideológicas ou políticas ele praticará ativismo judicial (ABBOUD E LUNELLI, 2015).

Para reforçar a ideia de bom ou mau ativismo, que é sempre equivocada, os autores trazem o artigo "Judicial Activism, by liberal and conservatives, is a danger to America" de Carson Holloway, com o julgamento do caso de Citizens Unitede vs. Federal Election Comission, no qual relata a história da inclusão de organizações particulares em campanhas políticas. É possível verificar no texto que a Suprema Corte julgou como inconstitucional a inclusão, em razão de violação à Emenda I da Constituição Norte-Americana, que garante a liberdade de expressão. Contudo, posteriormente, a decisão foi derrubada por cinco Justices, superando, inclusive, um precedente estabelecido.

Ainda no tocante a essa questão, os autores trazem a Suprema Corte dos Estados Unidos para exemplificar decisões que por lá foram tomadas, fundamentadas nas ideologias criadas pelos julgadores. O que se pode perceber acerca disso é que, em muitos casos, o ativismo judicial é criticado quando a decisão não agrada o grupo, que por, mostra-se insatisfeito, sendo utilizado sem qualquer reclamação quando a decisão é favorável, mesmo que contrarie a Carta Magna. Em outras palavras, pode-se dizer que, tanto os democratas quanto os conservadores repudiavam as decisões que lhe eram contrárias e faziam boas vistas para as que lhes favoreciam. Portanto, é possível perceber que quando a Suprema Corte anula uma lei ou derruba um precedente, aqueles que discordam dessa decisão costumam acusar a ocorrência de ativismo judicial.

No segundo artigo, os autores explanam o ativismo judicial comparando-o com miniconstituintes e para tanto utilizam a obra "A Odisseia" de Homero, em que o "canto das sereias" encanta e desvia os homens de seus objetivos, e, para solucionar este problema, Ulisses, personagem principal da obra, ordena que os seus subordinados o acorrentem e não o soltem de maneira alguma, nem mesmo, se ele, posteriormente emitisse uma ordem de soltura.

De forma bem interessante, os autores utilizaram da épica de Homero para explicar como as Constituições funcionam do mesmo modo que o ativismo judicial, uma vez que, segundo os autores, as Constituições são acorrentadas por meio do corpo político, já que é ele que fornece as restrições para não 
sucumbir ao despotismo das futuras maiorias. Contudo, deve-se notar, por meio da explicação de que é necessário obedecer à razão e não às paixões, e é por meio dessa frase que se têm os problemas do ativismo judicial.

Os autores ainda fazem referência ao jurista alemão Otto Bachof e trazem a sua obra "Normas constitucionais inconstitucionais?", escrita em 1994, para relembrar que, durante o período que se denominou guerra fria, o Tribunal Constitucional Federal da Alemanha instituiu uma jurisprudência de valores, relacionando esses pontos a uma tentativa de regulamentação da união homoafetiva pelo Supremo Tribunal Federal(STF) a pedido da Procuradoria-Geral da República.

O fato dos juristas aplicarem o direito por meio de argumentos pessoais e não por interpretação com base em alegações de princípios é debatido pelos autores quando estes fazem a seguinte pergunta sobre o caso de Bachof: "Haveria a possibilidade de dizer que as normas Constitucionais possam ser inconstitucionais, de modo a permitir uma alteração significativa de seu conteúdo?’. Apesar disso, o Tribunal Constitucional Federal legitimou a Lei Fundamental e a tese de Bachof não ressarciu.

Ocorre que, conforme é mencionado ainda neste segundo texto, há autores que acreditam que este posicionamento do Tribunal acarretou substancialmente na perda das certezas jurídicas. Outros estudiosos do tema falam ainda sobre as dificuldades de interpretações das novas Constituições que fundaram o Estado Democrático de Direito. E é por meio desses dois âmbitos interpretativos que os doutrinadores, trazendo alusão a obra de Bachof, refletem sobre as uniões homoafetivas via jurisprudências do STF.

Uma das diversas críticas explanadas pelos autores para a Arguição de Descumprimento de Preceito Fundamental (ADPF), pedindo a regularização da união homoafetiva, é o fato de que a Constituição Federal de 1988 diz explicitamente que o Estado deve proteger a união entre homem e mulher, de modo que alegar uma omissão do constituinte sobre o assunto não se sustenta, uma vez que o constituinte não se omitiu, muito pelo contrário, optou de forma expressa em resguardar os direitos dos casais heterossexuais, devendo a mudança para abranger casais do mesmo sexo ter que partir do legislativo, que é o órgão competente para tanto.

Nesse contexto, os autores citam como uma possível solução que os casais do mesmo sexo tenham os seus direitos julgados levando em conta o direito das obrigações e não o direito matrimonial e sucessório. Para tanto, mencionam ainda o caso ocorrido na Espanha em que uma lei foi editada a fim de resguardar os direitos dos homossexuais, não tendo o Poder Judiciário daquele país julgado em desacordo com a sua Constituição.

Assim, explicam que, através da argumentação da Procuradoria-Geral da República, a ideia de haver normas constitucionais/inconstitucionais aparece no parágrafo terceiro do artigo 226 da Constituição, pois está expresso que a proteção do Estado se remete entre o homem e a mulher, e assim contraria princípios sensíveis da Constituição, como é o caso da segurança jurídica e da dignidade da pessoa humana. Com isso, existe a necessidade de recorrer ao bom ativismo judicial para resolver as questões da sociedade. Mas, não existe o bem e o mal dentro deste tema, considerando-se, como é dito pelos autores, não se pode violar os princípios constitucionais da dignidade da pessoa humana, da igualdade, da vedação de discriminações 
odiosas, da liberdade e da proteção da segurança jurídica.

Considerando-se os argumentos até aqui apresentados, compreende-se que, o que os autores expressam é que o judiciário não pode julgar de acordo com o seu gosto pessoal, pois vivemos em um país democrático. Exemplificando essa abordagem, Streck, Barreto e Oliveira (2009) aduzem que se o judiciário fosse intervir em tudo, os interesses dos homossexuais estariam em risco, porque assim a relação entre as pessoas do mesmo sexo dependeria da vontade e da opinião de quem fosse julgar. Em vista disso, compreendem os autores que nas soluções de questões jurídicas, não poderá haver discordância acerca da decisão judicial. Além disso, afirmam que a população deve confiar na Constituição e na forma em que ela impõe as leis, e, jamais, alterá-la por questões pessoais, pois não se modifica nada por intermédio do ativismo judicial.

Os artigos, em particular, apresentam conceitos fundamentais na área, tratados de maneira didática e de fácil compreensão, possibilitando ao leitor uma experiência agradável e enriquecedora. Ainda que não se trate de uma leitura obrigatória, acreditamos que assim deveria ser para todos os estudantes de Direito, pois devido à relevância, os textos merecem espaço na análise acadêmica, por ser valioso saber que o ativismo judicial é uma postura discreta do Poder Judiciário frente ao Legislativo e Executivo, e nenhum julgador tem o direito de ignorar os textos legais.

Para finalizar, é possível perceber que os dois artigos trazem a crítica sobre o bom ou mau ativismo, portanto, tecemos aqui as nossas considerações em concordância com os autores, pois também enxergamos o ativismo como uma atividade perigosa à Democracia, uma vez que se trata de um afronte à Constituição Federal de 1988, devendo sempre evitar quaisquer atitudes que sejam pautadas tão somente em preceitos de cunho ideológicos, políticos e morais do julgador.

\section{REFERÊNCIAS BIBLIOGRÁFICAS:}

ABBOUD, Georges; LUNELLI, Guilherme. Ativismo judicial e instrumentalidade do processo: diálogos entre discricionariedade e democracia. Revista de Processo, vol. 242, p. 21-47. abr. 2015. Disponível em: http://www.bvr.com.br/abdpro/wp-content/uploads/2016/03/Ativismo-e-Instrumentalidade-do-Processov.-digital.pdf. Acesso em: 10 jan. 2020.

TASSINARI, Clarissa. Jurisdição e ativismo judicial: limites da atuação do judiciário. Porto Alegre: Livraria do Advogado Editora, 2018. 